\title{
Dp44mT regulates the levels of inflammatory mediators through blocking NF-KB nuclear translocation in LPS-stimulated RAW 264.7 macrophages
}

\author{
Jin-Ho Lim ${ }^{1} \cdot$ Hee-Yun Kim ${ }^{2} \cdot$ Jin Soo Lee ${ }^{3} \cdot$ Hyung-Min Kim ${ }^{3} \cdot$ Hyun-Ja Jeong ${ }^{1,2}$ \\ Received: 26 October 2020 / Accepted: 24 January 2021 / Published online: 16 February 2021 / Editor: Tetsuji Okamoto \\ (C) The Society for In Vitro Biology 2021
}

\begin{abstract}
Inflammation is increased by infection with pathogens such as viruses, bacteria, and parasites. High levels of inflammatory mediators and infiltration of macrophages into inflammatory lesions were reported in severe inflammatory diseases. Here, the aim of this study was to evaluate an anti-inflammatory activity of di-2-pyridylketone-4,4-dimethyl-3-thiosemicarbazone (Dp44mT) on lipopolysaccharide (LPS)-stimulated RAW 264.7 macrophages. Dp44mT (1-100 ng/mL) had no effect on viability of RAW 264.7 macrophages. Dp44mT (100 ng/mL) significantly reduced LPS-induced release of nitric oxide and expression of inducible nitric oxide synthase and cyclooxygenase-2. A significant upregulation of tumor necrosis factor (TNF)- $\alpha$ and interleukin (IL)-6 by LPS stimulation was downregulated by treatment with Dp44mT. Dp44mT blocked activation of nuclear factor- $\mathrm{kB}$ by the interruption of IKB $\alpha$ phosphorylation. Dp44mT suppressed the phagocytosis. Furthermore, administration of Dp44mT significantly reduced the serum levels of TNF- $\alpha$ and IL-6 in LPS-treated mice without side effects. In conclusion, these results indicate that Dp44mT has an anti-inflammatory activity and may be of therapeutic significant for the prevention and treatment of inflammatory diseases.
\end{abstract}

Keywords Dp44Mt $\cdot$ Nitric oxide $\cdot$ Cyclooxygenase- $2 \cdot$ Inflammatory cytokine $\cdot$ Nuclear factor-kB

\section{Introduction}

As severe acute respiratory syndrome coronavirus 2 has rapidly spread worldwide, there have been increasing reports from Asia, Europe, Latin America, and North America describing patients with COVID-19-associated multisystem inflammatory conditions ( $\mathrm{Li}$ et al. 2020). In severe patients with COVID-19, infiltration of monocytes and macrophages into lung lesions and high levels of inflammatory response because of the proinflammatory cytokine storm were reported (Zhang

Jin-Ho Lim and Hee-Yun Kim contributed equally to this work.

Hyun-Ja Jeong

hjjeong@hoseo.edu

1 Department of Bio-Convergence System, Graduate School, Hoseo University, 20 Hoseo-ro,79 Beon-gil, Baebang-eup, Asan 31499, Republic of Korea

2 Biochip Research Center, Hoseo University, 20, Hoseo-ro 79beon-gil, Baebang-eup, Asan, Chungnam 31499, Republic of Korea

3 Department of Pharmacology, College of Korean Medicine, Kyung Hee University, Seoul 130-701, Republic of Korea et al. 2020). Inflammation is a complex biological process in which a host identifies substances in or out of the body as nonself-antigens or self-antigens, and is increased by infection with pathogens such as viruses, bacteria, and parasites (Liu et al. 2020). A moderate inflammatory response helps the host to block the invasion of pathogens, whereas severe inflammatory response contributes to the pathogenesis of various of inflammatory diseases (Nam et al. 2017a; Liu et al. 2020). Various inflammatory mediators such as proinflammatory cytokines, nitric oxide (NO), adhesion molecules, and prostaglandin E2 (PGE2) are closely associated with the classical clinical symptoms of inflammation such as heat, swelling, pain, redness, and loss of function during the inflammatory process (Hwang et al. 2014). Some researchers have reported that activated macrophages are the major inflammatory cells, which arbitrate most molecular and cellular inflammatory networks via production a variety of inflammatory mediators (Mann et al. 2018; Liu et al. 2020). In inflammation, macrophages take charge of the phagocytosis, immunomodulation, and antigen presentation through releasing of a variety of cytokines and growth factors (Fujiwara and Kobayashi 2005).

The immune responses include the activation and infiltration of macrophages and subsequently followed by 
upregulation of various inflammatory mediators such as NO, tumor necrosis factor (TNF)- $\alpha$, and interleukin-6 (IL-6) to resist against pathogens such as viruses, bacteria, and parasites (Chiu et al. 2019). Lipopolysaccharide (LPS, bacterial endotoxin) can provoke macrophages to release inflammatory mediators including IL-6, TNF- $\alpha$, cyclooxygenase-2 (COX-2), $\mathrm{NO}$, and inducible NO synthase (iNOS) (Nam et al. 2017a). $\mathrm{NO}$, unorthodox messenger molecule, is produced by the enzymatic action the iNOS which is over-expressed during inflammation by LPS and cytokines (Hwang et al. 2014). These inflammatory mediators were upregulated by activation of nuclear factor (NF)-кB in LPS-stimulated RAW 264.7 macrophages (Hu et al. 2011). In inflammatory responses, inhibitory kappa $\mathrm{B}(\mathrm{I} \kappa \mathrm{B})$ is phosphorylated and degraded, and then, $\mathrm{NF}-\mathrm{KB}$ is translocated into the nucleus and then binds to the promoter regions of various inflammatory genes including IL6, TNF- $\alpha$, iNOS, and COX-2 (Lee et al. 2016). Therefore, suppressing inflammatory mediators as well as NF- $\mathrm{kB}$ activation would be the therapeutic strategy to diminish the damage and thus indirectly or directly blockade the progression of inflammatory diseases (Chiu et al. 2019).

Di-2-pyridylketone-4, 4-dimethyl-3-thiosemicarbazone (Dp44mT) is being developed as one of the most effective iron chelators with selective antitumor activity (Kovacevic et al. 2010; Li et al. 2016). Previous our studies reported that Dp44mT has an anti-allergic inflammatory activity in in vivo and in vitro models (Nam et al. 2017b; Kim et al. 2018). Currently, many studies are being conducted on antiinflammatory therapy to alleviate the cytokine storm of sever COVID-19 infection (Ioannis et al. 2020). Thus, we investigated the anti-inflammatory activity and underlying mechanisms of the Dp44mT on activated RAW 264.7 macrophages and in vivo inflammation model.

\section{Materials and methods}

Materials Mouse recombinant IL- 6 and TNF- $\alpha$, anti-murine IL- 6 and TNF- $\alpha$ antibodies, and biotinylated IL- 6 and TNF- $\alpha$ antibodies were obtained from R\&D Systems (Minneapolis, MN). LPS, dimethyl sulfoxide (DMSO), sodium nitrite, 3-(4,5-dimethylthiazol-2-yl)-2,5-diphenyltetrazolium bromide (MTT), and deferoxamine (DFX) were obtained from Sigma (St. Louis, MO). Antibodies of iNOS, COX-2, phosphorylated I I B $\alpha(p I \kappa B \alpha)$, NF-KB (p65), actin, poly (ADP-ribose) polymerase (PARP), histone, and glyceraldehyde 3-phosphate dehydrogenase (GAPDH) were purchased from Santa Cruz Biotechnology, Inc. (Santa Cruz, CA). Dulbecco's modified Eagle's medium (DMEM) containing $\mathrm{L}_{\text {-arginine }}$ $(84 \mathrm{mg} / \mathrm{L})$ and fetal bovine serum (FBS) were obtained from Gibco BRL (Grand Island, NY).
Cell culture RAW 264.7 macrophages were cultured in DMEM containing with $10 \%$ heat inactivated FBS, $100 \mathrm{mg} /$ $\mathrm{mL}$ streptomycin, and $100 \mathrm{U} / \mathrm{mL}$ penicillin at $5 \% \mathrm{CO}_{2}, 95 \%$ humidity, and $37^{\circ} \mathrm{C}$. Dp44mT was dissolved in DMSO and diluted in distilled water (final concentration $\leq 0.1 \%(\mathrm{v} / \mathrm{v})$ ). Dp44mT has been used at concentrations of $1,10,100 \mathrm{ng} / \mathrm{mL}$ according to previous study (Nam et al. 2017b). To specifically demonstrate the effect of Dp44mT, another iron chelator DFX was used as a control.

MTT assay RAW 264.7 macrophages $\left(3 \times 10^{5}\right.$ cells $)$ were incubated for $48 \mathrm{~h}$ after being treated with Dp44mT (1, 10, $100 \mathrm{ng} / \mathrm{mL})$. Cells were incubated with $20 \mu \mathrm{L}$ of a MTT solution $(5 \mathrm{mg} / \mathrm{mL})$ for $4 \mathrm{~h}$ at $5 \% \mathrm{CO} 2,95 \%$ humidity, and $37^{\circ} \mathrm{C}$. Consecutively, MTT formazan was dissolved in DMSO and the absorbance of each well was read using an enzyme-linked immunosorbent assay (ELISA) reader at 540 nm (Molecular Devices Corp., Sunnyvale, CA).

Measurement of nitrite concentration RAW 264.7 macrophages $\left(3 \times 10^{5}\right.$ cells) were pretreated with $\mathrm{Dp} 44 \mathrm{mT}(1,10$, $100 \mathrm{ng} / \mathrm{mL}$ ) for $1 \mathrm{~h}$. After $1 \mathrm{~h}$, cells were stimulated with LPS $(10 \mu \mathrm{g} / \mathrm{mL})$. To measure nitrite, supernatant was incubated with Griess reagent $\left(2.5 \% \mathrm{H}_{3} \mathrm{PO}_{4} / 0.1 \% \mathrm{~N}\right.$-(1-naphtyl)ethylenediamine dihydrochloride/1\% sulfanilamide) for 10 min. The absorbance at $540 \mathrm{~nm}$ was determined using an ELISA reader (Molecular Devices Corp.). $\mathrm{NO}_{2}^{-}$was analyzed by using sodium nitrite as a standard.

Western blot analysis For extraction of protein, cells were rinsed with ice-cold phosphate buffered saline (PBS) and then lysed in ice-cold RIPA buffer (containing protease inhibitor cocktail and phosphatase inhibitor). Extracted protein were separated through electrophoresis, the proteins were transferred to nitrocellulose membranes by electrophoretic transfer. The membranes were blocked in $6 \%$ bovine serum albumin for $1 \mathrm{~h}$, rinsed and then incubated with COX-2, iNOS, NF- $\mathrm{B}$, PARP, GAPDH, pI $\kappa$ B $\alpha$, or actin antibodies (Santa Cruz, CA) for $1 \mathrm{~h}$ at room temperature. After wash the membrane, the membranes were incubated for $30 \mathrm{~min}$ with horse radish peroxidase-conjugated secondary antibodies. The protein levels were visualized by an enhanced chemiluminescence assay according to the manufacturer's instructions (Amersham Corp. Newark, NJ).

Enzyme-linked immunosorbent assay The levels of IL-6 and TNF- $\alpha$ were analyzed following the manufacturer's instruction (R\&D Systems).

RNA isolation and quantitative real-time PCR for RNA analysis Total RNA isolation, cDNA synthesis, and real-time PCR (RT-PCR) were performed following previous study (Nam et al. 2017b). Each complementary DNA template was 
amplified using SYBR Green PCR Master Mix (Applied Biosystems, Carlsbad, CA) with gene specific primers (mouse IL-6 sense 5' CAC CAG CAT CAG TCC CAA GA 3', antisense 5' CCA GAA ACC GCT ATG AAG TTC CT 3', mouse TNF- $\alpha$ sense $5^{\prime}$ CAG ACC CTC ACA CTC AGA TCA TCT $3^{\prime}$, antisense $5^{\prime}$ CCT CCA CTT GGT GGT TTG CTA $3^{\prime}$, and mouse GAPDH sense 5' GGC AAA TTC AAC GGC ACA 3', antisense 5' GTT AGT GGG GTC TCG CTC CTG 3'). Transcription levels of cytokine were normalized to GAPDH. All data were measured using the $\Delta \Delta \mathrm{CT}$ method.

Transient transfection and luciferase assay NF- $\mathrm{KB}$ luciferase reporter gene constructs (pNF-kB-LUC, plasmid containing NF- $\mathrm{KB}$ binding site, Stantagen, La Jolla, CA) were transiently transfected into RAW 264.7 macrophages using the Lipofectamine 2000 (Invitrogen Co., Carlsbad CA). After 48 $\mathrm{h}$, transfected cells $\left(3 \times 10^{5}\right)$ were plated and stimulated with LPS $(10 \mu \mathrm{g} / \mathrm{mL})$. Dp44mT $(1,10,100 \mathrm{ng} / \mathrm{mL})$ was added $1 \mathrm{~h}$ before LPS stimulation. Cells were harvested $24 \mathrm{~h}$ after stimulation and washed in cold PBS before lysis in $100 \mu \mathrm{L}$ lysis buffer (Luciferase assay kit; Promega). After vortex mixing and centrifugation at $12 \times 000 \mathrm{~g}$ for $1 \mathrm{~min}$ at $4^{\circ} \mathrm{C}$, the supernatant was stored at $70^{\circ} \mathrm{C}$ until use in the luciferase assay. Cell extract $(20 \mu \mathrm{L})$ and $100 \mu \mathrm{L}$ of the luciferase assay reagent were mixed at room temperature. Luciferase activity was measured with a MicroLumat Plus luminometer, according to the manufacturer's protocol. All transfection experiments were performed in at least three different experiments.

Transcription factor enzyme-linked immunoassay (TF-EIA, DNA-binding assay) The cells were pretreated with Dp44mT

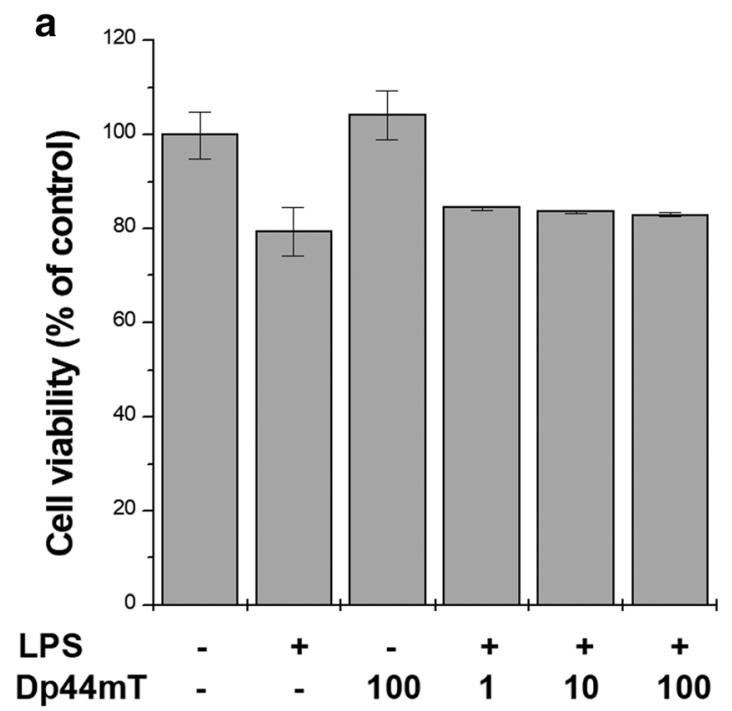

Figure 1. Effect of Dp44mT on cell viability in RAW 264.7 macrophages. (a) Cells were pretreated with Dp44mT (1, 10, $100 \mathrm{ng} /$ $\mathrm{mL})$ for $1 \mathrm{~h}$ and then stimulated with LPS $(10 \mu \mathrm{g} / \mathrm{mL})$ for $48 \mathrm{~h}$. Cell viability was determined with an MTT assay. The values from each treatment were expressed as a percentage relative to the control (100\%).
$(1,10,100 \mathrm{ng} / \mathrm{mL})$ for $1 \mathrm{~h}$ before LPS stimulation for $2 \mathrm{~h}$. We performed the TF-EIA for NF- $\mathrm{KB}$. Avidin was coated an a 96well ELISA plate. The coated plate was washed with PBST and then blocked with $3 \%$ skim milk solution. It was subsequently incubated with $1 \mu \mathrm{g} / \mathrm{mL}$ of 5'-biotinylated DNA oligonucleotide sequence (5'-AGT TGA GGG GAC TTT CCC AGG-3', NF-kB-binding motif) for $1 \mathrm{~h}$ at room temperature. DNA-binding reaction was carried out in a total volume of $100 \mu \mathrm{L}$ containing $10 \mu \mathrm{g}$ nuclear protein extract in a buffer containing $10 \mathrm{mM}$ HEPES (pH 7.9), $50 \mathrm{mM} \mathrm{NaCl}, 5 \%$ glycerol, $1 \mathrm{mM}$ EDTA, and $1 \mathrm{mM}$ DTT, for $1 \mathrm{~h}$ at room temperature and then washed. NF-KB antibodies were then added at a 1:500 concentration in PBS containing 3\% BSA for $1 \mathrm{~h}$, followed by the addition of the corresponding alkaline phosphatase (AP)-coupled secondary antibody. Between each addition, the wells were extensively washed in PBST. AP activity was then detected by the addition of p-nitrophenyl phosphate solution (Sigma). After a $10 \mathrm{~min}$ incubation period, the reaction was arrested by the addition of $0.5 \mathrm{M} \mathrm{H}_{2} \mathrm{SO}_{4}$. Color intensity was detected at $405 \mathrm{~nm}$ using an ELISA reader. AP activity was normalized to control values (unstimulated cells).

Phagocytosis assay Phagocytosis was analyzed following the manufacturer's instruction (Abchem, Cambridge, MA). In briefly, Phagocytosis Assay Kit (green E. coli) utilizes heatkilled, fluorescently pre-labeled E. coli particles. The cells were pretreated with Dp44mT $(1,10,100 \mathrm{ng} / \mathrm{mL})$ for $1 \mathrm{~h}$ and then add $5 \mu \mathrm{L}$ of $E$. coli slurry to all the wells. After $3 \mathrm{~h}$ incubation period, immediately measure fluorescence using plate reader at $\mathrm{Ex} / \mathrm{Em} 490 / 520 \mathrm{~nm}$.

b
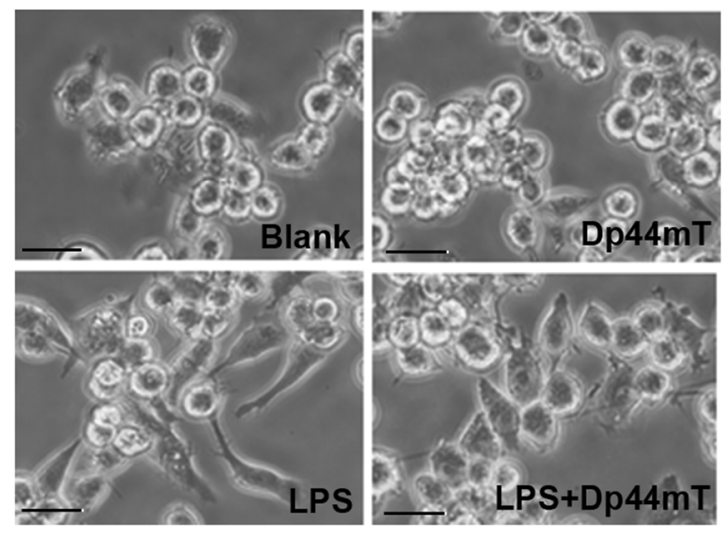

Each datum represents the mean \pm SEM of three independent experiments with duplicate. (b) Cells were pretreated with Dp44mT (100 ng/mL) for $1 \mathrm{~h}$ and then stimulated with LPS $(10 \mu \mathrm{g} / \mathrm{mL})$ for $48 \mathrm{~h}$. The morphology of cell was investigated by light microscopy. (Original magnification $x$ 400). 
Septic mice model The male C57BL/6 mice (7-9 wk old) was obtained from the Dae-Han Experimental Animal Center (Eumsung, Chungbuk, Republic of Korea). Mice were acclimated to individual cages during $7 \mathrm{~d}$ in a room with controlled lighting ( $12 \mathrm{~h}$ light-dark cycle), humidity (50-60\%), and temperature $\left(20-23^{\circ} \mathrm{C}\right)$. Experimental procedures and animal care were approved by the Animal Care Committee of Kyung Hee University (KHUASP (SE)-20-636). Dp44mT (100 $\mu \mathrm{g} / \mathrm{kg}$ ) or a control vehicle (distilled water) was orally administrated before LPS injection. Sepsis was induced in mice by intraperitoneal injection of LPS $(10 \mathrm{mg} / \mathrm{kg})$. Serum from heart was obtained $4 \mathrm{~h}$ after LPS according to the previous study (Han et al. 2019).

Blood biochemical parameters The levels of blood urea nitrogen (BUN), alanine transaminase (ALT), creatine kinase (CK), aspartate aminotransferase (AST), and lactate dehydrogenase (LDH) were analyzed by a DRI CHEM NX500 analyzer (Fujifilm, Tokyo, Japan).

Statistical analysis Data were shown as the mean \pm SEM of independent three experiments with duplicate, and an independent $t$-test was used for comparisons of normal and LPS stimulation conditions. In the comparisons of LPS stimulation and Dp44mT treatment conditions, an ANOVA with Tukey's post hoc test was used. Statistical significance was accepted for $P$ values $<0.05$.

\section{Results}

Effect of Dp44mT on viability of RAW 264.7 macrophages The relationship between the number of viable RAW 264.7 macrophages cells and the amount of formazan produced was investigated first. RAW 264.7 macrophages were treated with various concentrations of $\mathrm{Dp} 44 \mathrm{mT}(1,10$, and $100 \mathrm{ng} / \mathrm{mL})$ for $48 \mathrm{~h}$. As shown in Fig. $1 a$, Dp44mT (100 ng/mL) alone had no effect the viability of RAW 264.7 macrophages. We also investigated the effect of Dp44mT (1, 10, and $100 \mathrm{ng} / \mathrm{mL})$ on viability of LPS $(10 \mu \mathrm{g} / \mathrm{mL})$-stimulated macrophages. Treatment with Dp44mT did not cause the cytotoxicity on LPS-stimulated macrophages (Fig. 1a). In addition, morphology was not changed by treatment with Dp44mT $(100 \mathrm{ng} / \mathrm{mL}$, Fig. 1b). Therefore, we used the doses of 1,10 and $100 \mathrm{ng} / \mathrm{mL}$ to assess anti-inflammatory activity of Dp44mT on LPSstimulated RAW 264.7 macrophages. DFX also did not show the cytotoxicity (Supplementary Fig. 1).

\section{Suppressive effect of Dp44mT on NO production and iNOS} protein expression in LPS-stimulated RAW 264.7 macrophages $\mathrm{NO}$ generated by iNOS plays a pivotal role in various inflammatory diseases through acts as a stable toxic radical (Kim and Jeong 2015). We investigated whether Dp44mT could regulate NO production in LPS-simulated RAW 264.7 macrophages. Cells were treated with various concentrations of Dp44mT $(1,10$, and $100 \mathrm{ng} / \mathrm{mL})$ and then stimulate with LPS. LPS-stimulated macrophages significantly increased the NO production compared with the normal condition (Fig. $2 a$, $P<0.001)$. However, treatment with Dp44mT $(100 \mathrm{ng} / \mathrm{mL})$
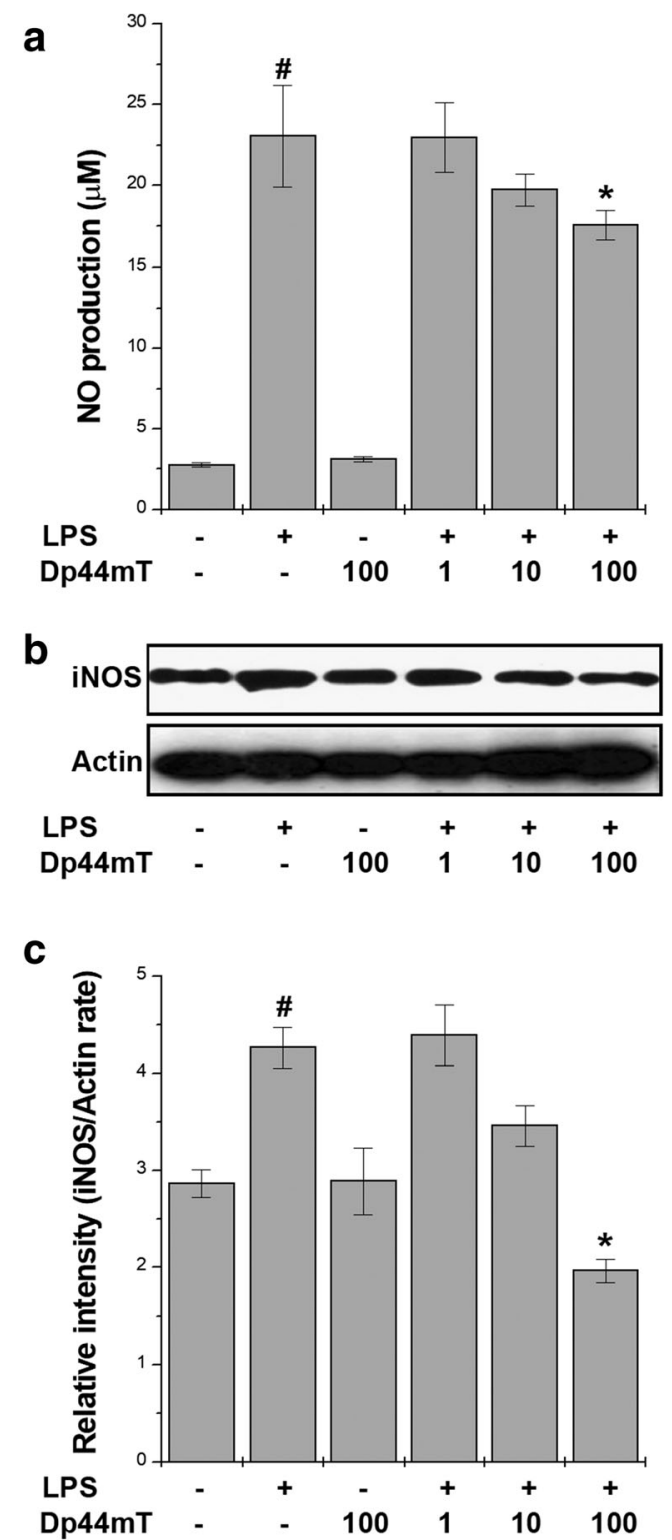

FIGURE. 2. Suppressive effect of Dp44mT on NO production and iNOS protein expression in LPS-stimulated RAW 264.7 macrophages. (a) Cells were pretreated with Dp44mT $(1,10,100 \mathrm{ng} / \mathrm{mL})$ for $1 \mathrm{~h}$ and then stimulated with LPS $(10 \mu \mathrm{g} / \mathrm{mL})$ for $48 \mathrm{~h}$. NO release was measured. (b) Cells were pretreated with Dp44mT $(1,10,100 \mathrm{ng} / \mathrm{mL})$ for $1 \mathrm{~h}$ and then stimulated with LPS $(10 \mu \mathrm{g} / \mathrm{mL})$ for $24 \mathrm{~h}$. The total proteins were determined for iNOS expression by Western blot analysis. Actin was used as a loading control. $(c)$ Each datum represents the mean \pm SEM of three independent experiments. Results are representative of three independent experiments. ${ }^{\#} P<0.05$ : significantly different from unstimulated cells; $* P<$ 0.05 : significantly different from LPS-stimulated cells. 
significantly decreased the NO production induced by LPS (Fig. $2 a, P<0.05$ ). DFX had no effect on LPS-induced NO production (Supplementary Fig. 2).

The regulatory effect of DP44mT on the protein levels of iNOS was analyzed by Western blotting. LPS stimulation significantly increased the iNOS expression in RAW 264.7 macrophages (Fig. $2 c$ and $2 c$ ) but treatment with Dp44mT (100 $\mathrm{ng} / \mathrm{mL}$ ) reduced this significantly increased iNOS expression (Fig. $2 b$ and $2 c$ ). Dp $44 \mathrm{mT}$ alone did not affect any changes the NO production and iNOS expression on RAW 264.7 macrophages (Fig. 2c).

\section{Suppressive effect of Dp44mT on COX-2 protein expression in} LPS-stimulated RAW 264.7 macrophages COX-2 expression is induced by inflammatory stimuli such as LPS (Ranganathan et al. 2013). COX-2 pathway is associated with inflammatory mediators, including NO, TNF- $\alpha$, IL-1 $\beta$, and IL-6 (Baradaran et al. 2019). Thus, we investigated the effect of Dp44mT on LPS-induced COX-2 expression in RAW 264.7 macrophages. When RAW 264.7 macrophages were stimulated with LPS, COX-2 expression was increased compared with the normal
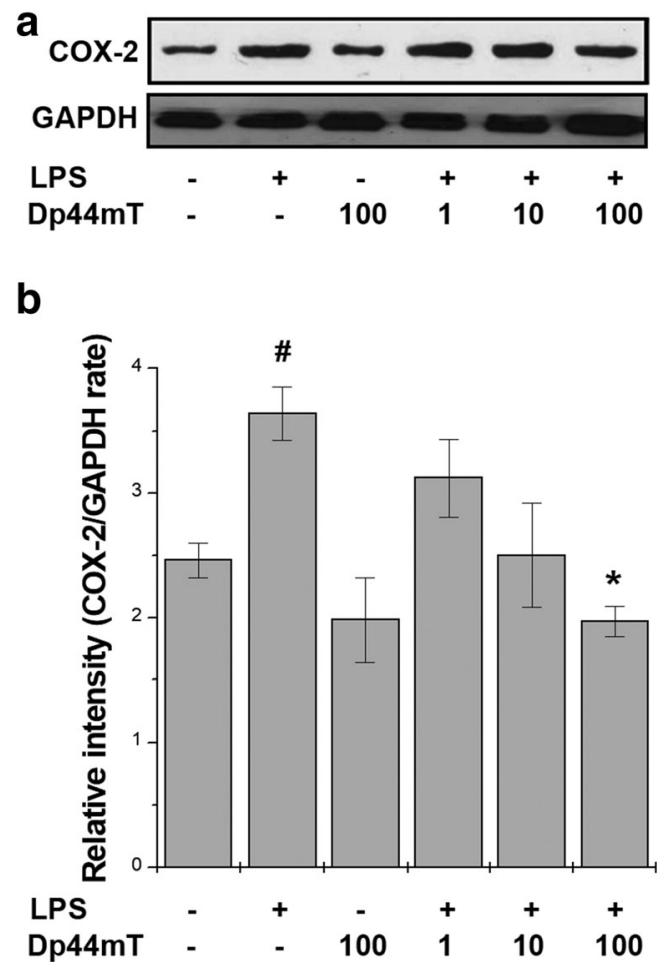

Figure 3. Suppressive effect of Dp44mT on COX-2 protein expression in LPS-stimulated RAW 264.7 macrophages. (a) Cells were pretreated with Dp44mT $(1,10,100 \mathrm{ng} / \mathrm{mL})$ for $1 \mathrm{~h}$ and then stimulated with LPS $(10 \mu \mathrm{g} /$ $\mathrm{mL}$ ) for $24 \mathrm{~h}$. The total proteins were determined for COX-2 expression by Western blot analysis. GAPDH was used as a loading control. (b) The relative COX-2 protein level was quantified by densitometry. Each datum represents the mean \pm SEM of three independent experiments. Results are representative of three independent experiments. ${ }^{\#} P<0.05$ : significantly different from unstimulated cells; $* P<0.05$ : significantly different from LPS-stimulated cells. condition, whereas treatment with Dp44mT decreased the LPS-induced COX-2 expression in a dose-dependent manner (Fig. 3). DFX had no effect on LPS-induced COX-2 expression (Supplementary Fig. 3).

Suppressive effect of Dp44mT on protein productions and mRNA expressions of IL- 6 and TNF- $\alpha$ in LPS-stimulated RAW 264.7 macrophages LPS is a well-known potential stimulator on production of inflammatory cytokines (Kim and Jeong 2015). The suppressive effect of Dp44mT on IL-6 and TNF- $\alpha$ production was investigated on LPS-simulated RAW 264.7 macrophages. Production levels of IL- 6 and TNF- $\alpha$
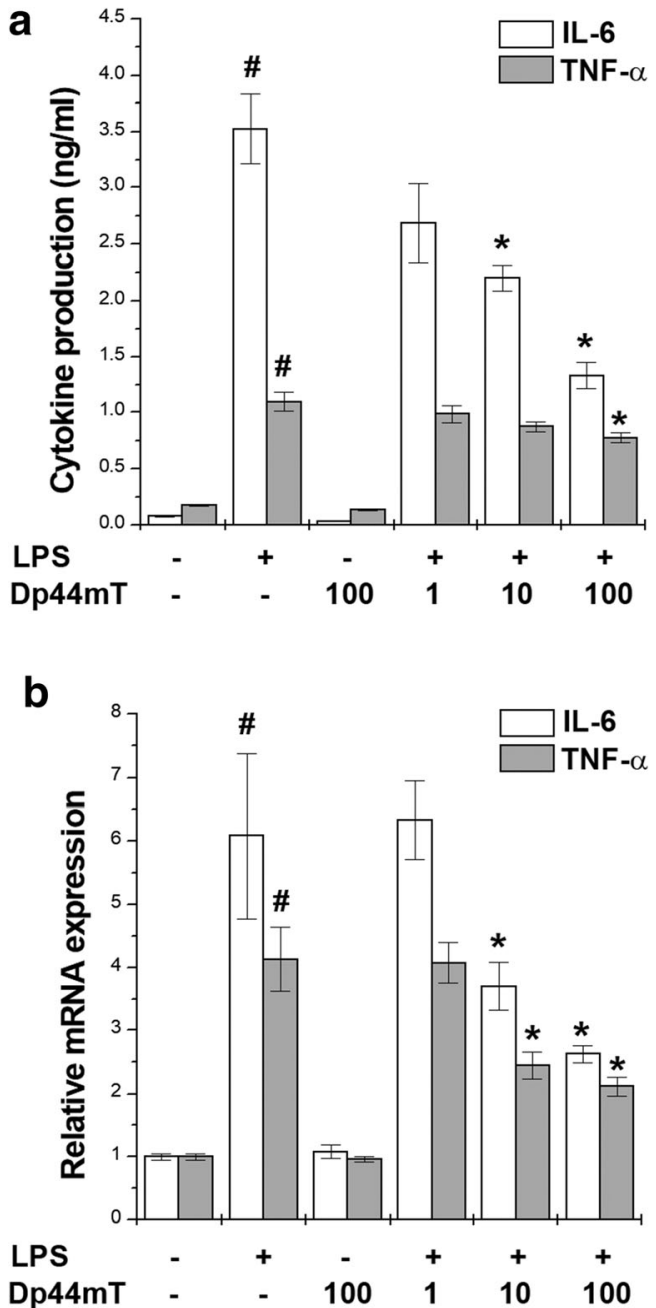

FIGURE 4. Suppressive effect of Dp44mT on protein productions and mRNA expressions of IL-6 and TNF- $\alpha$ in LPS-stimulated RAW 264.7 macrophages. (a) Cells were pretreated with Dp44mT $(1,10,100 \mathrm{ng} / \mathrm{mL})$ for $1 \mathrm{~h}$ and then stimulated with LPS $(10 \mu \mathrm{g} / \mathrm{mL})$ for $24 \mathrm{~h}$. The amounts of IL- 6 and TNF- $\alpha$ produced from macrophages were measured by ELISA method. (b) Cells were pretreated with Dp44mT $(1,10,100 \mathrm{ng} / \mathrm{mL})$ for $1 \mathrm{~h}$ and then stimulated with LPS $(10 \mu \mathrm{g} / \mathrm{mL})$ for $4 \mathrm{~h}$. The total RNA extracts were prepared, and then, the samples were analyzed for IL- 6 and TNF- $\alpha$ mRNA by RT-PCR. Each datum represents the mean \pm SEM of three independent experiments with duplicate. ${ }^{\#} P<0.05$ : significantly different from unstimulated cells; $* P<0.05$ : significantly different from LPS-stimulated cells. 

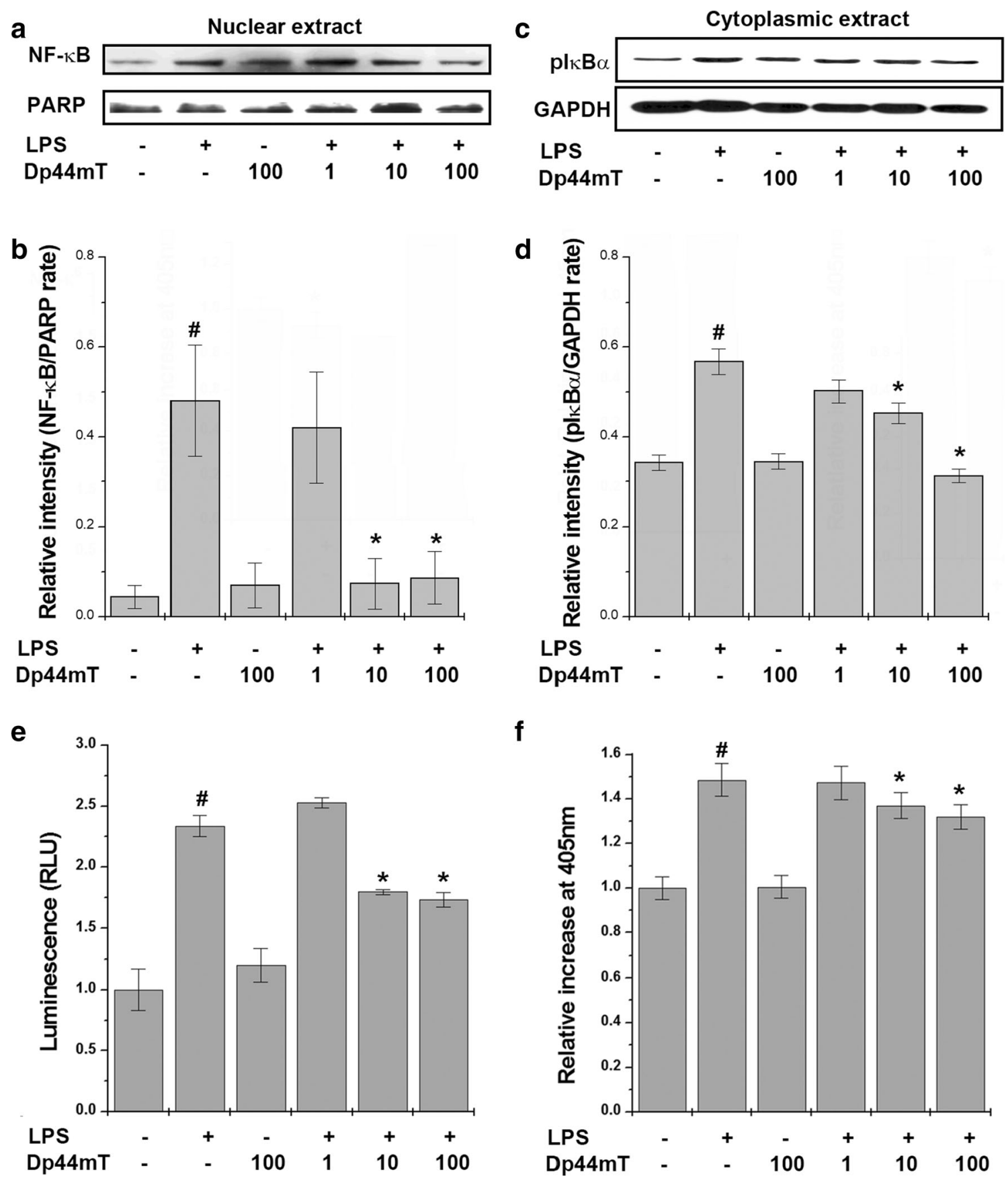

$\mathbf{f}$

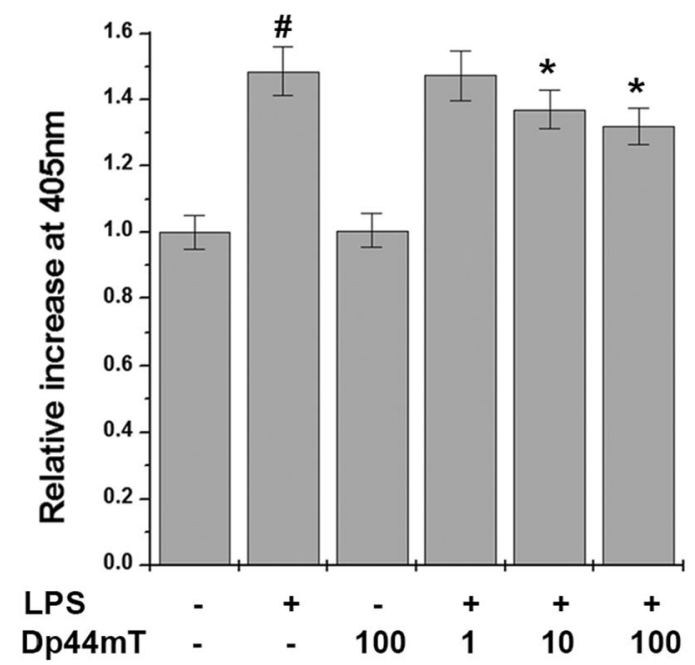

Figure 5. Suppressive effect of Dp44mT on NF-kB activation in LPSstimulated RAW 264.7 macrophages. Cells were pretreated with Dp44mT $(1,10,100 \mathrm{ng} / \mathrm{mL})$ for $1 \mathrm{~h}$ and then stimulated with LPS (10 $\mu \mathrm{g} / \mathrm{mL}$ ) for $2 \mathrm{~h}$. (a) The nuclear extracts were analyzed for NF-kB by Western blot analysis. (c) The cytoplasmic extracts were analyzed for phosphorylated $\mathrm{I} \kappa \mathrm{B} \alpha(\mathrm{pI} \kappa \mathrm{B} \alpha)$ by Western blot analysis. $(b, d)$ The relative NF- $\kappa B$ and $\mathrm{pI} \kappa \mathrm{B} \alpha$ protein levels were quantified by densitometry. PARP was used as a nuclear marker and a loading control. GAPDH was used as a loading control. (e) The NF- $\mathrm{KB}$ activity was assayed by luciferase assay and presented as relative luminescence units (RLU). $(f)$

Nuclear protein was incubated in a 96-well plate coated with an oligonucleotide containing the NF- $\mathrm{kB}$-binding site. The presence of an NF- $\mathrm{kB}$ transcription complex was evaluated with an NF- $\mathrm{kB}$ antibody. The result is expressed as the relative increase of the absorbance at $405 \mathrm{~nm}$ over control conditions. Each datum represents the mean \pm SEM of three independent experiments. Results are representative of three independent experiments. NE, nuclear extracts; CE, cytoplasmic extracts. ${ }^{\#} P<0.05$ : significantly different from unstimulated cells; $* P<0.05$ : significantly different from LPS-stimulated cells.

increased by LPS were significantly reduced by treatment with Dp44mT in a dose-dependent manner (Fig. $4 a, P<$ 0.05). We also examined the suppressive effect of Dp44mT

on mRNA expressions of IL- 6 and TNF- $\alpha$ in LPS-stimulated RAW 264.7 macrophages. The mRNA levels of IL-6 and TNF- $\alpha$ increased by LPS were significantly decreased by 
treatment with Dp44mT in a dose-dependent manner (Fig. $4 b$, $P<0.05)$. DFX had no effect on protein productions and mRNA expressions of IL- 6 and TNF- $\alpha$ in LPS-stimulated RAW 264.7 macrophages (Supplementary Fig. 4).

Suppressive effect of Dp44mT on NF-KB activation in LPSstimulated RAW 264.7 macrophages NF- $\mathrm{KB}$ plays a pivotal role in the mRNA expression of inflammatory genes such as iNOS, COX-2, IL-6, and TNF- $\alpha$ (Lee et al. 2016). We investigated the suppressive effect of Dp44mT on nuclear translocation of NF- $\mathrm{kB} / \mathrm{p} 65$ after LPS stimulation. As a result, treatment with Dp44mT suppressed the LPS-induced NF- $k B$ translocation into the nucleus (Fig. $5 a$ and $5 b$ ). Furthermore, treatment with Dp44mT blocked the LPS-induced IкB $\alpha$ phosphorylation in the cytosol (Fig. $5 c$ and $5 d$ ). We next examined whether Dp44mT could modulate the luciferase expression specifically via NF-kB. NF- $\mathrm{KB}$ luciferase reporter gene constructs were transiently transfected into RAW 264.7 macrophages, which was treated by $\mathrm{Dp} 44 \mathrm{mT}$ and then stimulated by LPS. As shown in Fig. 5e, LPS increased the reporter gene activity. However, the activity increased by LPS was significantly decreased by treatment with Dp44mT (Fig. $5 e, P<$ $0.05)$. We also investigated the suppressive effect of Dp44mT on LPS-induced NF- $\mathrm{kB}$ transcription complex. When RAW 264.7 macrophages were stimulated with LPS, DNA-binding activity for NF-KB was increased compared with the normal condition, whereas these increased binding activity was decreased by treatment with Dp44mT in a dosedependent manner (Fig. 5f). DFX had no effect on NF-kB activation in LPS-stimulated RAW 264.7 macrophages (Supplementary Fig. 5).

Suppressive effect of Dp44mT on phagocytosis Macrophages possess the ability to phagocytose and kill pathogens (Silva 2011). The suppressive effect of Dp44mT on phagocytosis was investigated on RAW 264.7 macrophages using fluorescent-labeled $E$. coli particles. As a result, treatment with Dp44mT $(100 \mathrm{ng} / \mathrm{mL})$ significantly decreased the phagocytosis of RAW 264.7 macrophages (Fig. $6, P<0.05$ ).

Suppressive effect of Dp44mT during sepsis Next, we investigated the anti-inflammatory effect of Dp44mT in LPSinduced septic mice model. The serum levels of IL- 6 and TNF- $\alpha$ in the LPS-treated mice were significantly increased compared with the normal mice (Fig. 7, $P<0.05$ ). Dp $44 \mathrm{mT}$ $(100 \mu \mathrm{g} / \mathrm{kg})$ significantly decreased the levels of IL-6 and TNF- $\alpha$ induced by LPS in the serum (Fig. $7, P<0.05$ ).

To analyze the side effect of the Dp44mT, levels of blood biochemical parameters were determined by using DRI CHEM NX500 analyzer. As shown in Table 1, levels of serum LDH, BUN, ALT, AST, and CK in the LPS-treated group were significantly higher than those the normal group, whereas Dp44mT-administered group significantly reduced the contents of serum LDH, BUN, ALT, AST, and CK compared to those of LPS-treated group $(P<0.05)$.

\section{Discussion}

In this study, we focused on anti-inflammatory activity and underlying mechanisms of Dp44mT on LPS-stimulated RAW 264.7 macrophages. We determined that Dp44mT has an antiinflammatory activity through blocking the inflammatory mechanism such as NF-kB signaling pathway.

Macrophage is a main cell in the immune response to foreign invaders such as pathogens and macrophage activated by bacterial LPS plays an important role in inflammatory reaction via production of NO, IL-6, and TNF- $\alpha$ (Jacobi 2002; Bharat Reddy and Reddanna 2009). Excess production of inflammatory mediators from macrophages is involved in many diseases including sepsis, pulmonary fibrosis, atherosclerosis, rheumatoid arthritis, and asthma (Bharat Reddy and Reddanna 2009 ). NO produced by iNOS is a critical signaling molecule which is associated with immune response, inflammation, angiogenesis, and neural development (Wang et al. 2019). COX-2 is prostaglandin endoperoxide synthase, and it catalyzes the biosynthesis of prostanoid, such as prostaglandins and thromboxane from arachidonic acid (Bian et al. 2019). In addition, COX-2 mediated the inflammatory reactions in humans. Therefore, COX-2 inhibitors are widely used as anti-inflammatory drugs (Wang et al. 2019). TNF- $\alpha$ produced by activated macrophages induces various biological responses, including inflammation, shock, apoptosis, and tissue injury (Kim and Jeong 2015). In addition, TNF- $\alpha$ increases the productions of inflammatory mediators and activation of $\mathrm{T}$ cells and other inflammatory cells (Kim and Jeong 2015). IL-6 is a proangiogenic, proinflammatory, and

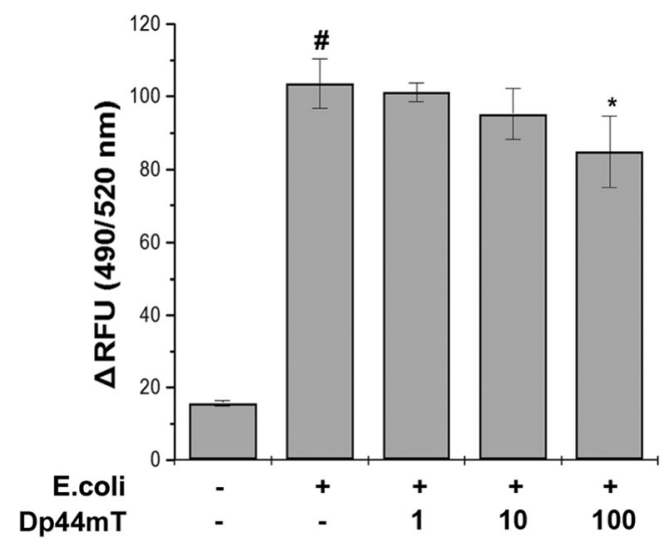

FiguRE 6. Suppressive effect of Dp44mT on phagocytosis. Cells were pretreated with $\mathrm{Dp} 44 \mathrm{mT}(1,10,100 \mathrm{ng} / \mathrm{mL})$ for $1 \mathrm{~h}$ and then stimulated with $E$. coli particles for $3 \mathrm{~h}$. The fluorescence was analyzed using plate reader at $\mathrm{Ex} / \mathrm{Em} 490 / 520 \mathrm{~nm}$ and presented as relative fluorescence units (RFU). Each datum represents the mean \pm SEM of three independent experiments. ${ }^{\#} P<0.05$ : significantly different from unstimulated cells; $* P<0.05$ : significantly different from $E$. coli particle-stimulated cells. 
FiguRE. 7 Suppressive effect of Dp44mT during sepsis. Dp44mT $(100 \mu \mathrm{g} / \mathrm{kg})$ or a control vehicle (distilled water) was orally administrated before LPS injection. Serum was isolated from blood and then assayed for (a) IL-6 and (b) TNF- $\alpha$ using the ELISA method. ${ }^{\#} P<0.05$ : significantly different from normal mice; $* P<0.05$ : significantly different from LPS-treated mice. $N=5 /$ group a

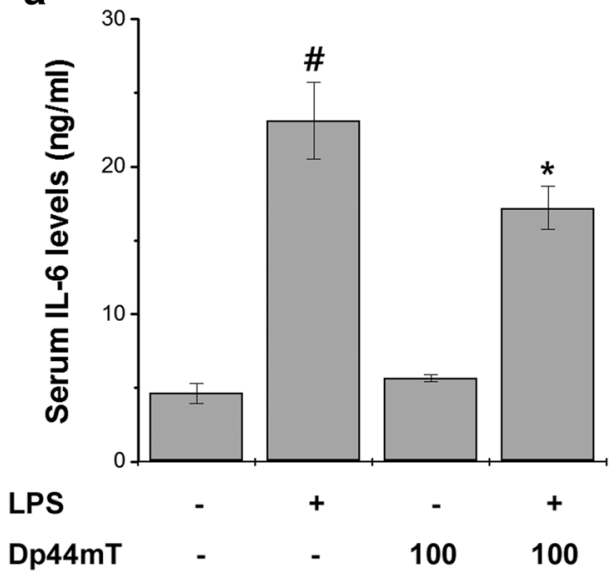

b

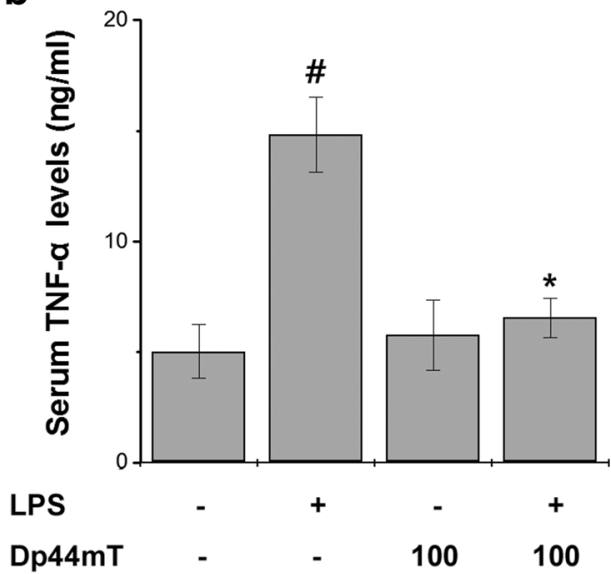

apoptotic cytokine and causes the pancreatitis-mediated lung injury and lethality. IL-6 mediated in innate and adaptive immune responses (Piao et al. 2019). Severe COVID-19 associated pneumonia patients may exhibit features of systemic hyper-inflammation designated under the umbrella term of macrophage activation syndrome or cytokine storm (McGonagle et al. 2020). The cytokine storm is an out-ofcontrol cytokine release that has been observed in some infectious and noninfectious diseases, leading to a hyperinflammation condition in the host (Mahmudpour et al. 2020). High levels of TNF- $\alpha$ and IL-6 were reported in patients with COVID-19 (Waleed et al. 2018; Chen et al. 2020). In this study, we showed that Dp44mT significantly suppressed the levels of NO, iNOS, COX-2, TNF- $\alpha$, and IL-6 in activated RAW 264.7 macrophages. Therefore, these results suggest that $\mathrm{Dp} 44 \mathrm{mT}$ has an anti-inflammatory activity through suppressing levels of inflammatory mediators on macrophage-mediated inflammatory reactions.

In this study, Dp44mT partially reduced the production of NO, TNF- $\alpha$, and IL- 6 and the expression of iNOS and COX2. In particular, the IC50 values of Dp44mT for NO and TNF- $\alpha$ inhibitory effects are approximately $6 \mu \mathrm{g} / \mathrm{mL}$ and $681 \mathrm{ng} / \mathrm{mL}$, respectively. It can be seen that the concentration of Dp44mT used in this study is very low. Therefore, further studies are needed to determine the complete inhibitory effect of Dp44mT at higher concentrations without cytotoxicity.

NF- $\mathrm{KB}$ regulates inflammatory response and their signaling pathways induce the expression of COX-2 and iNOS in LPS-stimulated macrophages (Jeong et al. 2014). Therefore, the inhibition of NF-KB nuclear translocation is viewed as a pivotal objective by those developing anti-inflammatory drugs (Kim and Jeong 2015). Dp44mT reduced proliferation of various cancer cells, including prostate cancer, neuroblastoma, pancreatic cancer, neuroepithelioma, colorectal cancer, breast cancer, and lung carcinoma through iron chelation and the generation of cytotoxic radicals (Li et al. 2016; Forciniti et al. 2020). Previous our study reported that $\mathrm{Dp} 44 \mathrm{mT}$ exerted an anti-allergic inflammatory activity through the inhibition of NF- $\mathrm{KB}$ in activated human mast cells (Nam et al. 2017b). In this study, we showed that treatment of Dp44mT significantly reduced the protein levels of translocated NF-KB in LPSstimulated RAW 264.7 macrophage. Therefore, these data suggest that Dp44mT has an anti-inflammatory activity through the downregulation of NF-KB activation in macrophage-mediated inflammatory reaction.

Phagocytosis is required for a wide variety of specialized biologic events and is the first step in triggering host defense and inflammation. Macrophages are an important mediator of
Table 1. Effects of Dp44mT on the blood biochemical parameters

\begin{tabular}{llllll}
\hline & LDH $(\mathrm{U} / \mathrm{L})$ & BUN $(\mathrm{mg} / \mathrm{dL})$ & ALT $(\mathrm{U} / \mathrm{L})$ & AST $(\mathrm{U} / \mathrm{L})$ & CK $(\mathrm{mg} / \mathrm{dL})$ \\
\hline Normal & $850 \pm 129.1$ & $13.73 \pm 0.73$ & $53.75 \pm 17.97$ & $115.75 \pm 23.73$ & $0.14 \pm 0.01$ \\
LPS & $5450 \pm 404.15^{\#}$ & $58.1 \pm 1.96^{\#}$ & $305.75 \pm 19.45^{\#}$ & $478.75 \pm 16.38^{\#}$ & $1.11 \pm 0.04^{\#}$ \\
Dp44mT & $1050 \pm 57.74$ & $19.35 \pm 0.66$ & $61.00 \pm 5.29$ & $117.75 \pm 8.77$ & $0.14 \pm 0.01$ \\
LPS + Dp44mT & $2057.5 \pm 370.44^{*}$ & $29.68 \pm 2.36^{*}$ & $133.00 \pm 10.13^{*}$ & $163.25 \pm 11.62^{*}$ & $0.23 \pm 0.01^{*}$ \\
\hline
\end{tabular}

Values are means \pm SEM

${ }^{\#} P<0.05$ vs. normal group

$* P<0.05$ vs. LPS group

$L P S$, LPS-treated group; $L P S+D p 44 m T, \mathrm{Dp} 44 \mathrm{mT}(100 \mu \mathrm{g} / \mathrm{kg})$-administered group 
inflammation and serve as phagocyte clearing microorganisms. Macrophages produces inflammatory mediators, including cytokines that further instruct the adaptive immune response during the phagocytosis (Dennison and Van Dyke 1997). In this study, Dp44mT significantly reduced the phagocytosis. Furthermore, administration of Dp $44 \mathrm{mT}$ decreased the levels of TNF- $\alpha$, and IL- 6 on serum of LPS-treated mice. Therefore, these data suggest that $\mathrm{Dp} 44 \mathrm{mT}$ has an antiinflammatory activity through blocking the activation of macrophage.

\section{Conclusion}

Conclusively, this study demonstrates that Dp44mT significantly alleviated the iNOS and COX-2 expression and suppressed the inflammatory cytokine production by blocking NF- $\mathrm{kB}$ activation. Furthermore, Dp44mT significantly reduced the phagocytosis and decreased the levels of inflammatory cytokines in septic mice. Thus, the unique abilities of Dp44mT to reduce the levels of NO, IL- 6 , and TNF- $\alpha$ suggest that it can be a strong candidate for the prevention and treatment of inflammatory diseases such as sepsis or COVID-19. However, inflammatory diseases complicated, and the antiinflammatory activity of Dp44mT in COVID-19 in vivo models was not investigated in this study. Therefore, further study is required to elucidate potential effects of $\mathrm{Dp} 44 \mathrm{mT}$ on various inflammation in vivo models before clinical applications.

Supplementary Information The online version contains supplementary material available at https://doi.org/10.1007/s11626-021-00552-y.

Funding This study was supported by grants from Basic Science Research Program through the National Research Foundation of Korea (NRF) funded by the Ministry of Education (2018R1D1A1B07042113).

\section{References}

Baradaran RV, Khammar MT, Rakhshandeh H, Samzadeh-Kermani A, Hosseini A, Askari VR (2019) Crocin protects cardiomyocytes against LPS-Induced inflammation. Pharmacol Rep 71:1228-1234

Bharat Reddy D, Reddanna P (2009) Chebulagic acid (CA) attenuates LPS-induced inflammation by suppressing NF- $\mathrm{KB}$ and MAPK activation in RAW 264.7 macrophages. Biochem Biophys Res Commun 381:112-117

Bian Y, Yang L, Zhang B, Li W, Wang S, Jiang S, Chen X, Li W, Zeng L (2019) Lincrna Cox-2 regulates lipopolysaccharide-induced inflammatory response of human peritoneal mesothelial cells Via Modulating Mir-21/NF-Kb axis. Mediators Inflamm 2019:8626703
Chen T, Wu D, Chen H, Yan W, Yang D, Chen G, Ma K, Xu D, Yu H, Wang H, Wang T, Guo W, Chen J, Ding C, Zhang X, Huang J, Han M, Li S, Luo X, Zhao J, Ning Q (2020) Clinical characteristics of 113 deceased patients with coronavirus disease 2019: retrospective study. BMJ 368:m1091

Chiu HF, Wang HM, Shen YC, Venkatakrishnan K, Wang CK (2019) Anti-inflammatory properties of fermented pine (Pinus morrisonicola Hay.) needle on lipopolysaccharide-induced inflammation in RAW 264.7 macrophage cells. J Food Biochem 43(11)

Dennison DK, Van Dyke TE (1997) The acute inflammatory response and the role of phagocytic cells in periodontal health and disease. Periodontol 2000 14:54-78

Forciniti S, Greco L, Grizzi F, Malesci A, Laghi L (2020) Iron metabolism in cancer progression. Int J Mol Sci 21(6):2257

Fujiwara N, Kobayashi K (2005) Macrophages in inflammation. Curr Drug Targets Inflamm Allergy 4(3):281-286

Han NR, Moon PD, Kim HM, Jeong HJ (2019) TSLP exacerbates septic inflammation via murine double minute 2 (MDM2) signaling pathway. J Clin Med 8(9):1350

Hu W, Yang X, Zhe C, Zhang Q, Sun L, Cao K (2011) Puerarin inhibits iNOS, COX-2 and CRP expression via suppression of NF- $\mathrm{KB}$ activation in LPS-induced RAW264.7 macrophage cells. Pharmacol Rep 63:781-789

Hwang SJ, Kim YW, Park Y, Lee HJ, Kim KW (2014) Antiinflammatory effects of chlorogenic acid in lipopolysaccharidestimulated RAW 264.7 cells. Inflamm 63:81-90

Ioannis Z, Ronan L, Catherine N, Alexandros T (2020) COVID-19: the inflammation link and the role of nutrition in potential mitigation. Nutrients 12:1466

Jacobi J (2002) Pathophysiology of sepsis. Am J Health Syst Pharm 59(Suppl 1):S3-S8

Jeong HJ, Han NR, Kim KY, Choi IS, Kim HM (2014) Gomisin A decreases the LPS-induced expression of iNOS and COX-2 and activation of RIP2/NF- $\mathrm{KB}$ in mouse peritoneal macrophages. Immunopharmacol Immunotoxicol 36:195-201

Kim HY, Han NR, Kim HM, Jeong HJ (2018) The iron chelator and anticancer agent $\mathrm{Dp} 44 \mathrm{mT}$ relieves allergic inflammation in mice with allergic rhinitis. Inflammation 41:1744-1754

Kim MH, Jeong HJ (2015) Zinc oxide nanoparticles suppress lps-induced $\mathrm{NF}-\mathrm{kB}$ activation by inducing $\mathrm{A} 20$, a negative regulator of NF- $\mathrm{KB}$, in RAW 264.7 macrophages. J Nanosci Nanotechnol 15:6509-6515

Kovacevic Z, Kalinowski DS, Lovejoy DB, Quach P, Wong J, Richardson DR (2010) Iron chelators: development of novel compounds with high and selective anti-tumour activity. Curr Drug Deliv 7:194-207

Lee SH, Kwak CH, Lee SK, Ha SH, Park J, Chung TW, Ha KT, Suh SJ, Chang YC, Chang HW, Lee YC, Kang BS, Magae J, Kim CH (2016) Anti-inflammatory effect of ascochlorin in LPS-stimulated RAW 264.7 macrophage cells is accompanied with the downregulation of iNOS, COX-2 and proinflammatory cytokines through NF-kB, ERK1/2, and p38 signaling pathway. J Cell Biochem 117: 978-987

Li J, Kun T, Mike L, Omar I, Shaun KM, Karen W, Jonathan DK, Zulfiqar AB (2020) COVID-19 and multisystem inflammatory syndrome in children and adolescents. Lancet Infect Dis S14733099(20):30651-30654

Li P, Zheng X, Shou K, Niu Y, Jian C, Zhao Y, Yi W, Hu X, Yu A (2016) The iron chelator Dp44mT suppresses osteosarcoma's proliferation, invasion and migration: in vitro and in vivo. Am J Transl Res 8: 5370-5385

Liu G, Xie J, Shi Y, Chen R, Li LI, Wang M, Zheng M, Xu J (2020) SecO-glucosylhamaudol suppressed inflammatory reaction induced by LPS in RAW264.7 cells through inhibition of NF- $\mathrm{kB}$ and MAPKs signaling. Biosci Rep 40:BSR20194230 
Mahmudpour M, Roozbeh J, Keshavarz M, Farrokhi S, Nabipour I (2020) COVID-19 cytokine storm: The anger of inflammation. Cytokine 133:155151

Mann M, Mehta A, Zhao JL, Lee K, Marinov GK, Garcia-Flores Y, Lu LF, Rudensky AY, Baltimore D (2018) An NF-kB-microRNA regulatory network tunes macrophage inflammatory responses. Nat Commun 9:3338

McGonagle D, Sharif K, O'Regan A, Bridgewood C (2020) The role of cytokines including interleukin-6 in COVID-19 induced pneumonia and macrophage activation syndrome-like disease. Autoimmun Rev 19:102537

Nam SY, Han NR, Yoon KW, Kim HM, Jeong HJ (2017b) Di-2pyridylketone 4,4-dimethyl-3-thiosemicarbazone (Dp44mT), an anticancer agent, exerts an anti-inflammatory effect in activated human mast cells. Inflamm Res 66:871-879

Nam SY, Kim KY, Kim MH, Jang JB, Rah SY, Chae HJ, Lee JM, Kim HM, Jeong HJ (2017a) Anti-inflammatory effects of a traditional Korean medicine: Ojayeonjonghwan. Pharm Biol 55:1856-1862

Piao X, Zou Y, Sui X, Liu B, Meng F, Li S, Zhang Q, Ma C, Wu T (2019) Hydrostatin-SN10 ameliorates pancreatitis-induced lung injury by affecting IL-6-induced JAK2/STAT3-associated inflammation and oxidative stress. Oxid Med Cell Longev 2019:9659757
Ranganathan PV, Jayakumar C, Mohamed R, Dong Z, Ramesh G (2013) Netrin-1 regulates the inflammatory response of neutrophils and macrophages, and suppresses ischemic acute kidney injury by inhibiting COX-2-mediated PGE2 production. Kidney International 83:1087-1098

Silva MT (2011) Macrophage phagocytosis of neutrophils at infammatory/infectious foci: a cooperative mechanism in the control of infection and infectious infammation. J Leukoc Biol 89:675-683

Waleed HM, Omar FK, Qibo Z, Hatim MM, Bandar AS (2018) MERS$\mathrm{CoV}$ infection in humans is associated with a pro-inflammatory Th1 and Th17 cytokine profile. Cytokine 104:8-13

Wang HM, Fu L, Cheng CC, Gao R, Lin MY, Su HL, Belinda NE, Nguyen TH, Lin WH, Lee PC, Hsieh LP (2019) Inhibition of LPS-induced oxidative damages and potential anti-inflammatory effects of Phyllanthus emblica extract via down-regulating NF- $\mathrm{kB}$, COX-2, and iNOS in RAW 264.7 cells. Antioxidants (Basel) 8:270

Zhang W, Zhao Y, Zhang F, Wang Q, Li T, Liu Z, Wang J, Qin Y, Zhang X, Yan X, Zeng X, Zhang S (2020) The use of anti-inflammatory drugs in the treatment of people with severe coronavirus disease 2019 (COVID-19): The Perspectives of clinical immunologists from China. Clin Immunol 214:108393 